\title{
Indoor Air Pollution and Respiratory Diseases in Rural Areas of North and Northeast Brazil
}

\author{
Giovani Baggio ${ }^{1}$, Cesar Augusto Oviedo Tejada ${ }^{2}$, Anderson M. Aristides dos Santos ${ }^{3} \&$ Lívia Madeira Triaca $^{4}$ \\ ${ }^{1}$ Federation of Industries of the State of Rio Grande do Sul, Porto Alegre, Rio Grande do Sul, Brazil \\ ${ }^{2}$ Postgraduate Program in Economics, Federal University of Pelotas, Pelotas, Rio Grande do Sul, Brazil \\ ${ }^{3}$ Institute of Economics, Business and Accounting, Federal University of Alagoas, Maceio, Brazil \\ ${ }^{4}$ Department of Economics, Federal University of Rio Grande, Rio Grande, Rio Grande do Sul, Brazil \\ Correspondence: Lívia Madeira Triaca, department of Economics, Federal University of Rio Grande, Km 8, \\ Italia Avenue, Rio Grande, RS 96203-900, Brazil. Tel 55-539-9129-2628. E-mail: liviamtriaca@ gmail.com
}

Received: October 2, 2018

Accepted: December 4, $2018 \quad$ Online Published: December 15, 2018

doi:10.5539/ijef.v11n1p66

URL: https://doi.org/10.5539/ijef.v11n1p66

\begin{abstract}
Indoor pollution is a risk factor for several diseases, especially those affecting the respiratory system. In Brazil, the use of solid fuels for cooking is still very present. The smoke emitted in the environment by the burning of solid fuels is causing such pollution, and the poorest families are the most affected. The objective of this research was to study the association between respiratory diseases (bronchitis and asthma) and the use of solid fuels among inhabitants of rural areas of the North and Northeast regions of Brazil. The database used was the 2008 National Household Sample Survey (PNAD/IBGE), and the analyzes involved estimations through the Logistic regression. The results showed that women exposed to indoor pollution had a higher odd of having bronchitis or asthma. This effect was not significant in the case of men. This work indicates a path for the implementation of public policies aimed at raising public awareness about the health damages caused by the use of solid fuels and facilitating access to a cleaner source of energy for the low-income population.
\end{abstract}

Keywords: indoor air pollution, respiratory diseases, bronchitis, asthma, Brazil

\section{Introduction}

Air pollution is usually associated with large urban centers. Images of factory chimneys and exhaust pipes are the first to be remembered when it comes to this theme. However, a large part of the world's population is exposed to another type of pollution that is as serious as that of large centers and most of the time unknown to people: indoor pollution.

In 2012, the early deaths around the world caused by external air pollution were 3.7 million and by indoor pollution were 4.3 million (WHO, 2014). Of these latest deaths, 3.8 million were caused by Noncommunicable Diseases (NCDs). In low- and middle-income countries (LMICs) it is estimated that indoor pollution causes $25 \%$ of all deaths from strokes, $15 \%$ of all deaths from ischemic heart disease, $17 \%$ of all lung cancer deaths, and more than $33 \%$ of all deaths from chronic obstructive pulmonary disease (COPD). In addition, women and children are particularly at high risk of becoming ill because they spend more time inside the house: $60 \%$ of all early deaths associated with indoor pollution occurs among them (WHO, 2016).

One of the main causes of indoor pollution is the smoke produced in the burning of solid fuels, which produces a large amount of harmful chemicals in the environment (Torres-Duque et al., 2008; WHO, 2016). Low-income families, mainly residents of rural areas, use this source of energy in the basic home needs, such as cooking, boiling water, heating the environment and even lighting. Solid fuels include coal and biofuels (wood, charcoal, manure and crop residues). About 3 billion people in the world cook or heat their homes using solid fuels (WHO, 2016).

The smoke produced by the burning of solid fuels, whether in internal or external environments, is the pollutant that presents greater toxicity and is associated with numerous diseases, mainly respiratory (WHO, 2016). Acute respiratory infections in children, chronic obstructive pulmonary disease (COPD), pneumoconiosis, cataract and blindness, pulmonary tuberculosis and adverse impacts on pregnancy are well documented effects in developing 
countries (Arbex et al., 2004; Cançado et al., 2006; Laumbach \& Kipen, 2012; Perez-Padilla et al., 2010; WHO, 2014).

The health damage caused by exposure to this type of pollution depends not only on the levels of pollutants in the environment, but also on the persistence of such exposure. Women, who usually cook and do household chores, are the most affected by indoor pollution. Children and the elderly are also greatly impaired by spending most of their time inside households (Breysse et al., 2010; WHO, 2016).

Developing countries, where biomass burning is the largest domestic source of energy, are those with the highest incidence of diseases associated with domestic pollution. The high cost of accessing and maintaining a more suitable source of energy, such as electricity and gas, leads the lower-income population to use the solid fuels that are the cheapest source of energy, and in many places the only affordable one (Bruce et al., 2000, 2002; Fullerton et al., 2008; WHO, 2016).

Data from the 2012 Brazilian Energy Balance (Enérgetica EDP, 2012), released by the Ministry of Mines and Energy, show that firewood is the second main source of residential energy in Brazil, accounting for $27.8 \%$ of the total consumption. The main source is electricity (41.7\%), and the third is liquefied petroleum gas, $27.2 \%$ (Enérgetica EDP, 2012).

The North and Northeast regions of Brazil have the highest proportion of people living in rural areas and with a higher incidence of poverty. Considering that a large part of the population of these regions may still be exposed to air pollution inside their homes, the objective of this research is to study the association between respiratory diseases and the use of solid fuels as residential energy source among adults in rural areas of Brazil in the North and Northeast regions, based on data from the 2008 National Household Sample Survey.

\section{Literature Review}

The literature that seeks to analyze the effects of indoor pollution on the health of the population focuses mainly on the members of households that are most exposed to this type of pollution, women and children. The literature is extensive; acute respiratory infections in children, chronic obstructive pulmonary disease (COPD), pneumoconiosis, cataract and blindness, pulmonary tuberculosis and adverse impacts on pregnancy are well documented effects in developing countries (Arbex et al., 2004; Cançado et al., 2006; Laumbach \& Kipen, 2012; Perez-Padilla et al., 2010; WHO, 2014). One of the research lines of this literature focuses specifically on the effect of indoor pollution on respiratory diseases (Dherami et al., 2008; Kurmi et al., 2010; Po et al., 2010; Wong et al., 2013; Gordon et al., 2014).

Dherami et al. (2008) point to the importance of reducing exposure to internal pollution caused by solid fuels for the prevention of childhood pneumonia. Through a meta-analysis, the authors investigated the association between the etiologic agent and the severity of pneumonia in 5-year-old children who are exposed to unprocessed solid fuels. The results showed that the risk of pneumonia in young children is increased by exposure to unprocessed solid fuels by a factor of 1.8 .

Kurmi et al. carry out a systematic review to analyze the impact of using different solid fuels in the development of chronic obstructive pulmonary disease (COPD) and chronic bronchitis. The authors observed positive associations between the use of solid fuels and COPD and chronic bronchitis. The evidence indicates that exposure to wood smoke is the form of solid fuel that presents greater risk to the development of the diseases.

Also through a systematic review, Po et al. (2010) analyze the association between the use of biomass fuels and respiratory outcomes in women and children living in rural areas. The results show that exposure to indoor pollution is associated with several respiratory diseases. Grouped odds ratios indicated significant associations with acute respiratory infection in children and chronic bronchitis and chronic obstructive pulmonary disease in women. However, no significant association was observed for asthma.

Wong et al. (2013) investigate the association between asthma and the use of a variety of cooking fuels throughout the world. The study analyzed two age groups, children from 6 to 7 years old and from 13 to 14 years old. The results show a higher risk of presenting symptoms or diagnosis of asthma in children living in households that use open fire for cooking in both age groups. As for the use of gas as cooking fuel, the authors did not observe evidence of significant association.

Gordon et al. (2014) review the evidence for the association between exposure to indoor air pollution and respiratory infections, respiratory tract cancers, and chronic lung diseases. The authors find significant associations for the three groups of diseases. According to their observations, respiratory infections, including infections of the upper and lower respiratory tract, were statistically associated with indoor pollution. Cancers were strongly associated with coal burning pollution and chronic lung diseases, including chronic obstructive 
pulmonary disease and bronchiectasis in women, were associated with the use of solid fuel for cooking.

Even though they are pointed out in the literature as an important risk factor for respiratory diseases, a large part of the world population still uses solid fuels for cooking, and although it is a highly present problem in low-income countries and poor areas, a good part of the studies was carried out in high-income countries. This article contributes with the aforementioned literature when analyzing the particular case of the poor areas of a middle-income country, Brazil.

\section{Methodology}

The data were taken from the National Household Sample Survey (PNAD), conducted in 2008 by the Brazilian Institute for Geography and Statistics (IBGE). PNAD is a national survey and it aims to produce basic information for the study of the country's socioeconomic development. The research presents periodical supplements on specific topics. In 2008, one of the addressed topics was the population's health, our reason for choosing this database. The PNAD sampling plan is carried out through three-stage clusters (municipalities, census tracts and residence). The sample design guarantees representativeness for the country, macroregions, states and some metropolitan regions. A total of 391,868 people and 150,591 households were surveyed in all Federal Units.

Only individuals from the rural area of the North and Northeast regions were selected for this study. Two reasons led to this choice: (1) as shown in Table 1, these two regions have the highest proportions of people living in the rural area $(28.67 \%$ in the Northeast and $27.26 \%$ in the North), with values well above the national average of $18.77 \%$; (2) according to Table 2, among the people in these regions using solid fuels, a large portion is in the first quartile of income in rural Brazil (43.64\% in the Northeast and $34.47 \%$ in the North), indicating that they are individuals with low purchasing power and who possibly have an inadequate stove. In other words, considering the type of fuel and this part of the population, a large amount of pollutants is possibly produced in the home environment.

Table 1. Number and proportion of people by census tract and living region (National Household Sample Survey - PNAD/IBGE, 2008)

\begin{tabular}{ccccccc}
\hline \multirow{2}{*}{ CENSUS TRACT } & \multicolumn{5}{c}{ REGION } & TOTAL \\
\cline { 2 - 5 } & North & Northeast & Southeast & South & Midwest & Then \\
\hline \multirow{2}{*}{ Urban } & 38,908 & 53,096 & 46,148 & 14,093 & 11,075 & 163,320 \\
& $72.74 \%$ & $71.33 \%$ & $91.91 \%$ & $85.30 \%$ & $91.32 \%$ & $81.23 \%$ \\
\multirow{2}{*}{ Rural } & 10,368 & 16,081 & 4,182 & 1,970 & 1,004 & 33,605 \\
& $27.26 \%$ & $28.67 \%$ & $8.09 \%$ & $14.70 \%$ & $8.68 \%$ & $18.77 \%$ \\
\multirow{2}{*}{ TOTAL } & 49,276 & 69,177 & 50,330 & 16,063 & 12,079 & 196,925 \\
& $100 \%$ & $100 \%$ & $100 \%$ & $100 \%$ & $100 \%$ & $100 \%$ \\
\hline
\end{tabular}

Table 2. Number and proportion of rural population using solid cooking fuels belonging to the 1st income quintile of the Brazilian rural area, separated by living region

\begin{tabular}{ccccccc}
\hline \multirow{2}{*}{$\begin{array}{c}\text { BELONGING TO THE 1ST } \\
\text { QUANTILE }\end{array}$} & North & Northeast & Southeast & South & Midwest & TOTAL \\
\cline { 2 - 6 } No & 1,904 & 6,875 & 2,467 & 2,380 & 737 & 14,363 \\
& $68.96 \%$ & $59.36 \%$ & $82.83 \%$ & $89.99 \%$ & $88.63 \%$ & $69.04 \%$ \\
\multirow{2}{*}{ Yes } & 1,054 & 4,526 & 506 & 271 & 93 & 3,983 \\
& $31.04 \%$ & $40.64 \%$ & $17.17 \%$ & $10.01 \%$ & $11.37 \%$ & $30.60 \%$ \\
\hline
\end{tabular}

Thus, our sample was concentrated in the poorest regions of Brazil, rural areas of the North and Northeast macroregions, where there is greater use of firewood/coal. After filtering and excluding observations with missing data for the variables of interest, the sample resulted in 22,485 individuals.

In this study, the outcome variable refers to the individual having bronchitis or asthma, information obtained through the following question: "Did any doctor or health professional say that you have bronchitis or asthma?". The answer is dichotomized in yes/no. These diseases are only two among a number of existing respiratory problems, but they were the only ones reported in the 2008 PNAD.

The main explanatory variable of interest was whether the individual was exposed to indoor pollution or not. In order to get this information, we used the answer on the main fuel used in the stove through the following 
question: "Is the stove in this house used predominantly?". The answers on canister gas, piped gas, electric power and other fuel were grouped into the category of clean fuels and the firewood and coal answers were grouped into the category of solid fuels. If the individual used solid fuel in the stove s/he was considered to be exposed to indoor pollution.

The control variables included in this study were divided into characteristics of household, place of residence, demographic and socioeconomic and health characteristics. Household characteristics included a variable that indicates the number of rooms, which was dichotomized in houses with only one room and in houses with two or more rooms. In households with just one room, pollution is more concentrated because there is no division between kitchen and dorms, what may not occur where there are more rooms. Sousa et al. (2012) have shown that having fewer rooms is associated with respiratory diseases, including bronchitis. A variable for overcrowded rooms was also included. It is well known that overcrowding is one of the risk factors for respiratory diseases (Prietsch et al., 2003). The variable was divided into households with less than three people per room and three or more people per room. In order to control geographical and cultural differences between the North and Northeast regions, a dummy was created that identifies the living region of each individual.

Demographic and socioeconomic characteristics included skin color (dichotomized as follows: white/yellow/indigenous and black/multirracial), age (grouped into seven categories: 18-29, 30-39, 40-49, 50-59 and 60 years old or older), education in years of study (grouped into five categories: 0 or <1, 1-3, 4-7, 8-10, 11 or more) and monthly per capita household income (separated in quintiles, the first quartile being the lowest income). The variables of income and education were included because, in addition to reflecting the person's socioeconomic position (which may influence the stove quality), they are correlated with access to and use of medicines, health services and more information about preventive measures, that is, with better health (Andrade et al., 2013).

The perception of the person's state of health is correlated with the presence of chronic diseases(Almeida et al., 2002). The self-assessed health status was dichotomized in good (very good/good) and bad (regular/bad/very bad).

One of the factors associated with the presence of respiratory diseases is the contact with smoking (Menezes, 1997; Menezes et al., 1994). People who reported smoking daily and currently some tobacco product were classified as active smokers. People who live in the same household with some active smoker and do not smoke were considered passive smokers.

The regressions were stratified by the sex variable because, especially in poor families, the woman is responsible for cooking and taking care of the children, being more exposed to indoor air pollution while the man goes out to work. Skin color categories were included to control the effects of culture and customs. Respiratory diseases like bronchitis and asthma are more common in children and in the elderly (Filho et al., 2004; Melsom et al., 2001; Mohamed et al., 1995; S. I. V. Sousa et al., 2012). In addition, children and the elderly stay longer at home and are more affected by indoor pollution (Breysse et al., 2010). Age categories were included to try to neutralize these differences. Moreover, children were seen to have a very specific health production function depending, for example, on indicators such as parental education, were removed, thus limiting the sample to adults (aged 18 or over).

The persistence of bronchitis/asthma and its respective 95\% confidence intervals were estimated according to household, demographic and socioeconomic characteristics, place of residence and health. A Pearson's Chi-Squared test was carried out to determine whether the differences between the categories were statistically significant.

In the multivariate analysis, odds ratios (OR) of bronchitis/asthma, according to the characteristics described above, were calculated with a Logistic regression model through an adjusted analysis.

All analyzes were carried out in the statistics software STATA 15.0. In order to consider the complexity of the PNAD sample plan, the survey module available in the package was used. The svyset command defined the sample weights and conglomerates, and the svy prefix was used in all the analyzes to contemplate the sample design.

\section{Results}

The persistence of bronchitis/asthma among individuals living in rural areas of the North and Northeast Brazil involved in the analysis was $2.6 \%$ (95\% CI $2.3 \%-2.8 \%)$. It was observed that the proportion of people in our sample who used solid materials as the main fuel for the stove and possibly were exposed to indoor pollution was $38.6 \%$. Table 3 presents the prevalence of the studied outcome according to characteristics of the household, 
place of residence, demographic, socioeconomic and health. A chi-square test was carried out to determine whether the differences between the categories were statistically significant.

For women, the prevalence of bronchitis/asthma was 3.52\% among those who were exposed to indoor pollution, a higher value in relation to people using clean fuels $(2.65 \%)$, and this difference was statistically significant. However, the difference among men was not statistically significant, while the overcrowding variables at home, living region and skin color were not statistically significant for either men or women.

In terms of age, the persistence was higher among the elderly (60 years or older) with a statistically significant difference in the two samples (men and women). As for education, in the sample of women there was no statistical significance, but for men the prevalence of bronchitis/asthma was in the brackets of the uneducated or under 1 year of study and for those who were 11 or older.

Regarding income, the first quintile had the lowest persistence of this outcome for men and the second lowest for women, differences in persistence were significant among quintiles, a fact observed for both sexes.

Individuals who consider their health status as regular, bad or very bad (bad self-assessed health) had a higher persistence of bronchitis/asthma than those reporting a good or very good health status (good self-assessed health). For example, the respective persistences for women were $5.05 \%$ and $1.52 \%$, with the difference between them being statistically significant.

Women who had contact with smoking in the home environment, either actively or passively, presented a higher persistence of bronchitis/asthma in relation to those who did not, but for men there was no statistically significant difference.

Table 3. Persistence of bronchitis/asthma according to individual characteristics of the rural population in the North and Northeast Brazil (National Household Sample Survey - PNAD/IBGE, 2008)

\begin{tabular}{|c|c|c|c|c|}
\hline & $\%(\mathrm{IC})$ & p-value & $\%(\mathrm{IC})$ & p-value \\
\hline & Women & & Men & \\
\hline \multicolumn{5}{|l|}{ Stove fuel } \\
\hline Clean fuels & $2.65(2.31-3.04)$ & \multirow{2}{*}{0.006} & $2.19(1.83-2.63)$ & \\
\hline Solid fuels & $3.52(2.96-4.19)$ & & $2.18(1.65-2.87)$ & 0.956 \\
\hline \multicolumn{5}{|l|}{ Household overcrowding } \\
\hline Less than 3 persons per room & $2.95(2.62-3.32)$ & & $2.21(1.87-2.60)$ & \\
\hline 3 or more persons per room & $4.36(1.79-10.24)$ & 0.381 & $0.64(0.00-4.42)$ & 0.187 \\
\hline \multicolumn{5}{|l|}{ Living region } \\
\hline North & $3.29(2.79-3.88)$ & & $2.28(1.50-3.43)$ & \\
\hline Northeast & $2.89(2.50-3.35)$ & 0.251 & $2.16(1.81-2.58)$ & 0.822 \\
\hline \multicolumn{5}{|l|}{ Skin color } \\
\hline White/Yellow/Indigenous & $3.05(2.69-3.45)$ & & $2.17(1.77-2.67)$ & \\
\hline Black/Multirracial & $2.76(2.09-3.65)$ & 0.517 & $2.23(1.71-2.90)$ & 0.883 \\
\hline \multicolumn{5}{|l|}{ Age } \\
\hline 18 to 29 & $2.41(1.92-3.01)$ & & $1.64(1.24-2.16)$ & \\
\hline 30 to 39 & $3.22(2.51-4.12)$ & & $1.69(1.23-2.32)$ & \\
\hline 40 to 49 & $2.61(1.91-3.56)$ & & $1.73(1.11-2.72)$ & \\
\hline 50 to 59 & $3.10(2.33-4.12)$ & & $2.13(1.55-2.92)$ & \\
\hline 60 or over & $3.98(3.06-5.15)$ & 0.040 & $4.44(3.47-5.67)$ & 0.000 \\
\hline \multicolumn{5}{|l|}{ Education (years) } \\
\hline 0 or $<1$ & $3.32(2.63-4.17)$ & & $2.82(2.27-3.50)$ & \\
\hline 1 to 3 & $3.10(2.47-3.88)$ & & $1.84(1.32-2.54)$ & \\
\hline 4 to 7 & $2.57(2.01-3.30)$ & & $1.61(1.10-2.36)$ & \\
\hline 8 to 10 & $3.44(2.46-4.81)$ & & $1.49(0.98-2.26)$ & \\
\hline 11 or over & $2.39(1.73-3.30)$ & 0.299 & $2.89(1.90-4.36)$ & 0.006 \\
\hline \multicolumn{5}{|l|}{ Income in quartiles } \\
\hline 1 (lower) & $2.75(2.29-3.29)$ & & $1.62(1.27-2.06)$ & \\
\hline 2 & $3.24(2.61-4.01)$ & & $2.56(1.97-3.34)$ & \\
\hline 3 & $2.40(1.77-3.26)$ & & $2.72(2.13-3.46)$ & \\
\hline 4 & $3.50(2.56-4.78)$ & & $2.61(1.69-4.01)$ & \\
\hline 5 & $5.53(3.63-8.34)$ & 0.010 & $2.24(1.17-4.26)$ & 0.016 \\
\hline
\end{tabular}




\begin{tabular}{lcccc}
\hline Health & & & & \\
Self-assessed health & $5.05(4.36-5.84)$ & & $4.52(3.79-5.38)$ & \\
Regular. bad and very bad & $1.52(1.25-1.84)$ & 0.000 & $0.95(0.74-1.22)$ & 0.000 \\
Good and Very good & & & & \\
Contact with smoking (active or passive smoker) & $2.67(2.29-3.10)$ & & $2.08(1.70-2.56)$ & \\
$\quad$ No & $3.54(2.93-4.26)$ & 0.020 & $2.35(1.93-2.87)$ & 0.315 \\
$\quad$ Yes & 10.721 & & 11.764 & \\
$\mathrm{~N}$ (observations) & & & \\
\hline
\end{tabular}

Table 4 presents the results of the multivariate analysis. The adjusted odds ratios were estimated using a logistic regression model. The results show that women possibly exposed to indoor pollution present a $43 \%$ higher odd of having bronchitis/asthma in relation to the unexposed ones. The effect for men is not statistically significant at $5 \%$.

Income was significant only for women and the last quintile. where they are more likely to have bronchitis/asthma compared to women in the first income quintile. Education was significant only for men who had 11 years of schooling or more. who presented higher chances of having bronchitis/asthma than those without education.

Among individuals who have declared their health to be very good or good, the odds of having bronchitis/asthma is $72.9 \%$ lower compared to people who declare their health as regular, bad or very bad. Contact with smoking (active or passive) was shown to have significant effect only for women. The other variables were not statistically significant.

Table 4. Odds ratios of factors associated with bronchitis/asthma in the population living in the rural area of the North and Northeast of Brazil (PNAD/IBGE. 2008)

\begin{tabular}{|c|c|c|c|c|}
\hline \multirow{3}{*}{ VARIABLES } & \multicolumn{4}{|c|}{ ODDS RATIOS (OR) } \\
\hline & Adjusted & P-value & Adjusted & P-value \\
\hline & \multicolumn{2}{|l|}{ Women } & \multicolumn{2}{|c|}{ Men } \\
\hline \multicolumn{5}{|l|}{ Stove fuel } \\
\hline Solid fuels & $1.429 * * *$ & 0.004 & 1.023 & 0.899 \\
\hline \multicolumn{5}{|l|}{ Household overcrowding } \\
\hline 3 or more persons per room & 1.412 & 0.467 & 0.317 & 0.252 \\
\hline \multicolumn{5}{|l|}{ Living region } \\
\hline Northeast & 0.876 & 0.269 & 0.890 & 0.611 \\
\hline \multicolumn{5}{|l|}{ Skin color } \\
\hline Black/Multirracial & 0.909 & 0.553 & 1.010 & 0.953 \\
\hline \multicolumn{5}{|l|}{ Age } \\
\hline 30 to 39 & 1.129 & 0.535 & 0.902 & 0.644 \\
\hline 40 to 49 & 0.781 & 0.307 & 0.728 & 0.258 \\
\hline 50 to 59 & 0.840 & 0.400 & 0.778 & 0.278 \\
\hline 60 or over & 1.061 & 0.811 & 1.306 & 0.223 \\
\hline \multicolumn{5}{|l|}{ Education (years) } \\
\hline 1 to 3 & 1.042 & 0.802 & 0.799 & 0.260 \\
\hline 4 to 7 & 0.986 & 0.946 & 0.862 & 0.533 \\
\hline 8 to 10 & $1.536^{*}$ & 0.079 & 0.946 & 0.816 \\
\hline 11 or over & 1.090 & 0.738 & $1.839^{* *}$ & 0.031 \\
\hline \multicolumn{5}{|l|}{ Income in quintiles } \\
\hline 2 & 1.210 & 0.231 & $1.369^{*}$ & 0.094 \\
\hline 3 & 0.810 & 0.328 & 1.229 & 0.245 \\
\hline 4 & 1.307 & 0.219 & 1.189 & 0.516 \\
\hline 5 (higher) & $2.614 * *$ & 0.000 & 1.045 & 0.916 \\
\hline \multicolumn{5}{|l|}{ Self-assessed health } \\
\hline Good/Very good & $0.271 * * *$ & 0.000 & $0.205 * * *$ & 0.000 \\
\hline \multicolumn{5}{|c|}{ Contact with smoking (active or passive smoker) } \\
\hline Yes & $1.291 * *$ & 0.047 & 1.137 & 0.346 \\
\hline $\mathrm{N}$ (observations) & \multicolumn{2}{|c|}{10,721} & \multicolumn{2}{|c|}{11,764} \\
\hline
\end{tabular}

Note. $* * * \mathrm{p}<0.01$. $* * \mathrm{p}<0.05$. $* \mathrm{p}<0.1$. 


\section{Discussion}

In 2008, the use of solid fuels as an energy source represented a large share of residential energy in Brazil. with the sum of fuels such as firewood and coal accounting for more than a third of the total (Enérgetica EDP, 2009). As the historical evolution of energy consumption in Brazil shows, the trend is to decrease the use of such fuels, but there are still many families with possible exposure to air pollution inside their homes. Indoor air pollution was identified as a major challenge in the early 21 st century for being one of the major environmental and public health problems in developing countries (Bruce et al., 2000).

The results indicate that women from rural areas of the North and Northeast regions exposed to indoor pollution are more susceptible to having bronchitis or asthma. which is in agreement with several studies (Kiraz et al., 2003; Mohamed et al., 1995; Pandey, 1984). It is worth noting that the results indicated statistical significance of firewood/charcoal use only for women. The literature shows controversial results: several studies point out that women are the most affected by indoor pollution and thus are at higher risk of getting diseases, but there are also studies that indicate men as the most affected (Arbex et al., 2004; Melsom et al., 2001). Discrimination between the sexes has been decreasing in every way. It is possible that by entering the labor market, women are no longer at home and thus less exposed to pollution.

People living in single-room households with three or more residents per room were not significantly associated with persistence of bronchitis/asthma. One study found that people living in households with a separate kitchen, that is, with more than one room, had a lower relative chance of having tuberculosis and found no relation to overcrowding (Mishra et al., 1999). Another study found a relation between overcrowding and bronchitis in a study carried out for São Paulo (Sousa et al., 2012). One of the reasons we did not find the relation between the studied diseases and those variables could be the small number of people living in households with those characteristics in our sample.

Some groups of the variables that represent the socioeconomic position, education and income showed a positive association with the persistence of bronchitis/asthma in some categories, different from those found in the literature. With improvements in socioeconomic conditions, individuals tend to choose more efficient and safer sources of energy (Bruce et al., 2000). The literature shows that this relationship is negative, that is, with increased income and education the persistence of bronchitis and asthma decreases (Menezes et al., 1994; Stanković et al., 2011). However, we should point out that in general the sample population has a low level of income, with $59 \%$ having a per capita household income below half a minimum wage and $84 \%$ below a minimum wage. It should be noted that one of the World Health Organization's bulletins in 2005 showed that there is a strong association between poverty and the use of solid fuels (Blakely et al., 2005).

Men and women who assessed their health status as regular, bad, and very bad had a higher persistence of bronchitis or asthma. A study analyzing the 1998 PNAD data shows that the persistence of chronic diseases (including bronchitis and asthma) is associated with bad self-assessed health status (Almeida et al., 2002).

As for the contact with smoking, it is already well documented in the literature its association with the studied diseases, mainly with bronchitis (Macedo et al., 2007; Menezes, 1997). Smoking is pointed out as the main cause of the development of chronic bronchitis (Menezes, 1997).

Therefore, this study showed that indoor pollution is associated with the persistence of bronchitis and asthma for women in rural areas of the North and Northeast regions of Brazil. The results show a significant and positive impact of the use of firewood/coal on the persistence of these diseases.

Low-income people are the most exposed because they do not have access to a cleaner source of energy and because they have less efficient combustion stoves. No associations of diseases with low-income people were found; on the contrary, the lowest socioeconomic status was shown in some cases as a protection factor. However, several studies show that people with higher income and more education have a lower risk of having diseases and the relationship of indoor pollution with various health problems is already well documented in the literature. In future research a more in-depth analysis should be carried out in this regard.

Therefore, the implementation of public policies can be important in order to eliminate damages to health, especially to women, from the use of solid fuels and to facilitate access to a cleaner source of energy.

One limitation of the work is that most of today's wood stoves have a system that does not pollute the home environment and therefore even the person using solid fuels does not suffer from the presence of air pollution inside the house. An example of this is the clean burning wood stove (Borges, 1994). Another limitation is that the self-reporting of the studied diseases is not the best method to know whether the individual really has the disease. With clinical analyzes the results would be more precise. However. several studies also used 
self-reported diseases and pointed out the association with pollution (Mishra et al., 1999; Mustapha et al., 2011).

\section{References}

Almeida, M. F. de, Barata, R. B., Montero, C. V., \& Silva, Z. P. da. (2002). Prevalência de doenças crônicas auto-referidas e utilização de serviços de saúde, PNAD/1998, Brasil. Ciência \&amp; Saúde Coletiva, 7(4), 743-756. https://doi.org/10.1590/S1413-81232002000400011

Andrade, M. V., Noronha, K. V. M. de S., Menezes, R. de M., Souza, M. N., Reis, C. de B., Martins, D. R., \& Gomes, L. (2013). Desigualdade socioeconômica no acesso aos serviços de saúde no Brasil: Um estudo comparativo entre as regiões brasileiras em 1998 e 2008. Economia Aplicada, 17(4), 623-645. https://doi.org/10.1590/S1413-80502013000400005

Arbex, M. A., Cançado, J. E. D., Pereira, L. A. A., Braga, A. L. F., \& Saldiva, P. H. do N. (2004). Biomass burning and its effects on health. Jornal Brasileiro de Pneumologia, 30(2), 158-175. https://doi.org/10.1590/S1806-37132004000200015

Blakely, T., Hales, S., Kieft, C., Wilson, N., \& Woodward, A. (2005). The global distribution of risk factors by poverty level. Bulletin of the World Health Organization, 83(2), 118-126.

Borges, T. P. de F. (1994). Fogão a lenha de combustão limpa (Dissertação de Metrado (Master Degree)). UNICAMP.

Breysse, P. N., Diette, G. B., Matsui, E. C., Butz, A. M., Hansel, N. N., \& McCormack, M. C. (2010). Indoor air pollution and asthma in children. Proceedings of the American Thoracic Society, 7(2), 102-106. https://doi.org/10.1513/pats.200908-083RM

Bruce, N., Perez-Padilla, R., \& Albalak, R. (2000). Indoor air pollution in developing countries: A major environmental and public health challenge. Bulletin of the World Health Organization, 78(9), 1078-1092.

Bruce, N., Perez-Padilla, R., \& Albalak, R. (2002). The health effects of indoor air pollution exposure in developing countries. Geneva. World Health Organization. Recuperado de http://apps.who.int/iris/handle/10665/67496

Cançado, J. E. D., Braga, A., Pereira, L. A. A., Arbex, M. A., Saldiva, P. H. N., \& Santos, U. de P. (2006). Clinical repercussions of exposure to atmospheric pollution. Jornal Brasileiro de Pneumologia, 32, S5-S11. https://doi.org/10.1590/S1806-37132006000800003

Dherani, M., Pope, D., Mascarenhas, M., Smith, K. R., Weber, M., \& Bruce, N. (2008). Indoor air pollution from unprocessed solid fuel use and pneumonia risk in children aged under five years: A systematic review and meta-analysis. Bulletin of the World Health Organization, 86, 390-398C. https://doi.org/10.2471/BLT.07.044529

Enérgetica EDP. (2009). Balanço Energético Nacional 2009 - Ano base 2008. Rio de Janeiro/BR.

Enérgetica EDP. (2012). Balanço Energético Nacional 2012 - Ano base 2011. Rio de Janeiro/BR. Recuperado de https://ben.epe.gov.br/downloads/Resultados_Pre_BEN_2012.pdf

Filho, L., De, A. I., Leite Matos, D., Giatti, L., Afradique, M. E., Viana Peixoto, S., \& Lima-Costa, M. F. (2004). Causas de internações hospitalares entre idosos brasileiros no âmbito do Sistema Único de Saúde. Epidemiologia e Serviços de Saúde, 13(4), 229-238.

Fullerton, D. G., Bruce, N., \& Gordon, S. B. (2008). Indoor air pollution from biomass fuel smoke is a major health concern in the developing world. Transactions of the Royal Society of Tropical Medicine and Hygiene, 102(9), 843-851. https://doi.org/10.1016/j.trstmh.2008.05.028

Gordon, S. B., Bruce, N. G., Grigg, J., Hibberd, P. L., Kurmi, O. P., Lam, K. B. H., ... \& Bar-Zeev, N. (2014). Respiratory risks from household air pollution in low and middle income countries. The Lancet Respiratory Medicine, 2(10), 823-860. https://doi.org/10.1016/S2213-2600(14)70168-7

Kiraz, K., Kart, L., Demir, R., Oymak, S., Gulmez, I., Unalacak, M., \& Ozesmi, M. (2003). Chronic pulmonary disease in rural women exposed to biomass fumes. Clinical and Investigative Medicine. Medecine Clinique Et Experimentale, 26(5), 243-248.

Kurmi, O. P., Semple, S., Simkhada, P., Smith, W. C. S., \& Ayres, J. G. (2010). COPD and chronic bronchitis risk of indoor air pollution from solid fuel: a systematic review and meta-analysis. Thorax, 65(3), 221-228. https://doi.org/10.1136/thx.2009.124644

Laumbach, R. J., \& Kipen, H. M. (2012). Respiratory health effects of air pollution: Update on biomass smoke 
and traffic pollution. The Journal of Allergy and Clinical Immunology, 129(1), 3-11. https://doi.org/10.1016/j.jaci.2011.11.021

Macedo, S. E. C., Menezes, A. M. B., Knorst, M., Dias-da-Costa, J. S., Gigante, D. P., Olinto, M. T. A., \& Fiss, E. (2007). Fatores de risco para a asma em adultos, Pelotas, Rio Grande do Sul, Brasil. Cadernos de Saúde Pública, 23(4), 863-874. https://doi.org/10.1590/S0102-311X2007000400014

Melsom, T., Brinch, L., Hessen, J. O., Schei, M. A., Kolstrup, N., Jacobsen, B. K., ... Pandey, M. R. (2001). Asthma and indoor environment in Nepal. Thorax, 56(6), 477. https://doi.org/10.1136/thorax.56.6.477

Menezes, A. M. B. (1997). Epidemiologia da bronquite crônica e do enfisema (DPOC): até onde sabemos? Jornal Brasileiro de Pneumologia, 23(3), 153-157.

Menezes, A. M., Victora, C. G., \& Rigatto, M. (1994). Prevalence and risk factors for chronic bronchitis in Pelotas, RS, Brazil: A population-based study. Thorax, 49(12), 1217-1221. https://doi.org/10.1136/thx.49.12.1217

Mishra, V. K., Retherford, R. D., \& Smith, K. R. (1999). Biomass cooking fuels and prevalence of tuberculosis in India. International Journal of Infectious Diseases: IJID: Official Publication of the International Society for Infectious Diseases, 3(3), 119-129. https://doi.org/10.1016/S1201-9712(99)90032-2

Mohamed, N., Ng'ang'a, L., Odhiambo, J., Nyamwaya, J., \& Menzies, R. (1995). Home environment and asthma in Kenyan schoolchildren: A case-control study. Thorax, 50(1), 74-78. https://doi.org/10.1136/thx.50.1.74

Mustapha, B. A., Blangiardo, M., Briggs, D. J., \& Hansell, A. L. (2011). Traffic air pollution and other risk factors for respiratory illness in schoolchildren in the niger-delta region of Nigeria. Environmental Health Perspectives, 119(10), 1478-1482. https://doi.org/10.1289/ehp.1003099

Pandey, M. R. (1984). Domestic smoke pollution and chronic bronchitis in a rural community of the Hill Region of Nepal. Thorax, 39(5), 337-339. https://doi.org/10.1136/thx.39.5.337

Perez-Padilla, R., Schilmann, A., \& Riojas-Rodriguez, H. (2010). Respiratory health effects of indoor air pollution. The International Journal of Tuberculosis and Lung Disease: The Official Journal of the International Union Against Tuberculosis and Lung Disease, 14(9), 1079-1086.

Po, J. Y., FitzGerald, J. M., \& Carlsten, C. (2011). Respiratory disease associated with solid biomass fuel exposure in rural women and children: Systematic review and meta-analysis. Thorax, 66(3), 232-239. https://doi.org/10.1136/thx.2010.147884

Prietsch, S. O. M., Fischer, G. B., César, J. A., Lempek, B. S., Jr, B., V, L., ... Santos, A. M. (2003). Doença respiratória em menores de 5 anos no sul do Brasil: influência do ambiente doméstico. Revista Panamericana de Salud Pública, 13, 303-310. https://doi.org/10.1590/S1020-49892003000400005

Seaton, A., MacNee, W., Donaldson, K., \& Godden, D. (1995). Particulate air pollution and acute health effects. Lancet (London, England), 345(8943), 176-178. https://doi.org/10.1016/S0140-6736(95)90173-6

Sousa, C. A. de, César, C. L. G., Barros, M. B. de A., Carandina, L., Goldbaum, M., \& Pereira, J. C. R. (2012). Respiratory diseases and associated factors: population-based study in São Paulo, 2008-2009. Revista de Saúde Pública, 46(1), 16-25. https://doi.org/10.1590/S0034-89102011005000082

Sousa, S. I. V., Ferraz, C., Alvim-Ferraz, M. C. M., Vaz, L. G., Marques, A. J., \& Martins, F. G. (2012). Indoor air pollution on nurseries and primary schools: Impact on childhood asthma - study protocol. BMC Public Health, 12(1), 435. https://doi.org/10.1186/1471-2458-12-435

Stanković, A., Nikolić, M., \& Arandjelović, M. (2011). Effects of indoor air pollution on respiratory symptoms of non-smoking women in Niš, Serbia. Multidisciplinary Respiratory Medicine, 6(6), 351-355. https://doi.org/10.1186/2049-6958-6-6-351

Torres-Duque, C., Maldonado, D., Pérez-Padilla, R., Ezzati, M., Viegi, G., \& Forum of International Respiratory Studies (FIRS) Task Force on Health Effects of Biomass Exposure. (2008). Biomass fuels and respiratory diseases: A review of the evidence. Proceedings of the American Thoracic Society, 5(5), 577-590. https://doi.org/10.1513/pats.200707-100RP

WHO. (2014). WHO indoor air quality guidelines: Household fuel combustion. Geneva: World Health Organization.

WHO. (2016). Burning opportunity: Clean household energy for health, sustainable development, and wellbeing 
of women and children. Geneva: World Health Organization.

\section{Copyrights}

Copyright for this article is retained by the author(s), with first publication rights granted to the journal.

This is an open-access article distributed under the terms and conditions of the Creative Commons Attribution license (http://creativecommons.org/licenses/by/4.0/). 